\title{
Safety and efficacy of probiotics in the prevention of necrotizing enterocolitis in premature and/or low-birthweight infants: a systematic review and meta-analysis
}

\author{
Hua Liu ${ }^{1 \#}$, Bin Wang ${ }^{2 \#}$, Tiantian Lu' ${ }^{1}$, Yuying Pei $^{3}$ \\ ${ }^{1}$ Department of Neonatology, Haikou Hospital of the Maternal and Child Health, Haikou, China; ${ }^{2}$ Department of Pharmacy, Haikou Hospital of \\ the Maternal and Child Health, Haikou, China; ${ }^{3}$ Department of Pediatrics, Central South University Xiangya School of Medicine Affiliated Haikou \\ Hospital, Haikou, China \\ Contributions: (I) Conception and design: H Liu; (II) Administrative support: Y Pei; (III) Provision of study materials or patients: B Wang; (IV) \\ Collection and assembly of data: T Lu; (V) Data analysis and interpretation: H Liu; (VI) Manuscript writing: All authors; (VII) Final approval of \\ manuscript: All authors. \\ \#These authors contributed equally to this work and should be considered as co-first authors. \\ Correspondence to: Yuying Pei. Department of Pediatrics, Central South University Xiangya School of Medicine Affiliated Haikou Hospital, Haikou \\ 570208, China. Email: peiyuying2140@163.com.
}

\begin{abstract}
Background: Neonatal necrotizing enterocolitis (NEC) is a serious pediatric gastrointestinal disease and a cause of death in neonates, especially in premature infants. The addition of probiotics to the diet can reduce the incidence and severity of neonatal NEC. This meta-analysis explored the preventive effect of probiotics on NEC.

Methods: Endnote X9 software was used to search for relevant studies in the Ovid, Embase, PubMed, and Web of Science databases. The search terms were "probiotics" and "necrotizing enterocolitis". After retrieval, screening, and quality evaluation of the studies, Stata 16.0 software was used to analyze the data.

Results: A total of 10 studies, which collectively included 3,227 patients, were selected for analysis. Of them, 5 used a multiple-strain probiotics, and 5 used single-strain probiotic. Meta-analysis showed that treatment with probiotics could reduce the incidence of severe NEC [risk ratio (RR) $=0.66$; $95 \%$ confidence interval (CI): $(0.50,0.87) ; \mathrm{Z}=-2.978 ; \mathrm{P}=0.003]$, reduce mortality in underweight premature children [RR $=0.81 ; 95 \%$ CI: $(0.70,0.94) ; Z=-2.864 ; P=0.004]$, and reduce the incidence of feeding intolerance $[R R=0.78$; 95\% CI: $(0.67,0.90) ; Z=-3.280 ; P=0.001]$.
\end{abstract}

Discussion: The addition of probiotics to the diet of low-birthweight and premature infants can reduce the incidence of severe NEC and reduce related mortality rates.

Keywords: Probiotics; preterm infants; low-birthweight infants; necrotizing enterocolitis; meta-analysis

Submitted Dec 27, 2021. Accepted for publication Feb 14, 2022.

doi: $10.21037 / \mathrm{tp}-22-27$

View this article at: https://dx.doi.org/10.21037/tp-22-27

\section{Introduction}

\section{Background}

Neonatal necrotizing enterocolitis (NEC) is a serious pediatric gastrointestinal disease and a cause of death in neonates, especially premature infants (1). In pediatric intensive care units, $90 \%$ of newborns with NEC are premature, and lower gestational ages and birthweights carry a higher probability of NEC. In very-low-birthweight (VLBW) premature infants, the incidence of NEC can reach $7 \%$ (2). The mortality rate of NEC is between $15 \%$ and $30 \%$, while the mortality rate of severe NEC requiring surgical intervention is up to $40 \%$ or $50 \%$. In the case of survivals of severe NEC, there are long-term adverse 
effects, such as infection, malnutrition, dysplasia, and retinal disease which could bring low quality of life for the children (3). The occurrence of NEC may be associated with various factors such as immature intestinal development, ischemia and hypoxia, dysbacteriosis, and a disturbed immune response in premature infants, but there is no complete pathogenesis (4). NEC begins with intestinal epithelial injury and bacterial invasion, causing an inflammatory cascade that leads to intestinal perforation, necrosis, sepsis, and death. The symptoms of NEC in children are diverse, including bradycardia, unstable body temperature, abdominal distension, abdominal pain, vomiting, and hematochezia with intestinal obstruction and pneumatosis intestinalis observed with radiological examination (5).

\section{Purpose}

Previous studies have suggested that advocating breastfeeding, dietary additions of epidermal growth factor or erythropoietin, or oral arginine may prevent NEC $(6,7)$. In recent years, many controlled clinical studies have investigated the role of probiotics in preventing NEC, and researchers have found that adding probiotics to the diet can reduce the incidence and severity of NEC (8). A metaanalysis conducted by Athalye-Jape et al. (9) included 29 studies and showed that the addition of probiotics reduced the incidence of NEC in premature VLBW newborns from $60 \%$ to $31.7 \%$. However, but the outcome indicator of the meta-analysis was limited to NEC rates, not including different serious grade of NEC and the analysis did not distinguish between the species of probiotics. There is a need of meta-analysis to reassess the role of probiotics in NEC prevention with new indicators and subgroup analysis based on multiple- or single-strain probiotics. We carried out a new meta-analysis on this topic, adding several indicators and comparing the preventive effect of multipleand single-strain probiotics on NEC to better understand the preventive effect of probiotics as a clinical reference.

We present the following article in accordance with the PRISMA reporting checklist (available at https:// tp.amegroups.com/article/view/10.21037/tp-22-27/rc).

\section{Methods}

\section{Inclusion criteria}

We defined the inclusion of eligible studies according to the
PICOS criteria (Patients, Intervention, Control, Outcome, Study).

\section{Study type}

We searched for randomized controlled trials (RCTs). Quasi- and non-randomized controlled clinical trials (CCTs) were excluded.

\section{Participants}

All patients were premature infants. As the criteria for defining premature delivery varies, the studies selected for this analysis had to include a definition of premature delivery, clearly specifying the gestational age of the study participants, which was generally 34 weeks. Participants were all VLBW neonates, with a bodyweight lower than $1,500 \mathrm{~g}$ as the standard.

\section{Intervention}

All selected studies randomly divided newborns into experimental and control groups. Newborns in the two groups were breastfed. Those in the experimental group had probiotics added to their diet, while those in the control group were given either a placebo or no addition to their diet. We did not limit the species of probiotics or whether the probiotics were multiple-strain. Studies that added nonprobiotics, such as prebiotics and synbiotics, were excluded.

\section{Control}

All studies needed to be grouped according to random methods. We did not limit whether the allocation concealment was used in the study or whether the blind method was described, but we would conduct bias analysis and quality evaluation before analysis.

\section{Outcome indicators}

The studies did not need to have a set follow-up time to be considered, but they needed to describe the start and end points of the treatments. For our statistical analysis, the main outcome indicators were as follows: (I) incidence of patients with NEC stage $\geq 2$; (II) mortality. Secondary outcomes indicators were the following: (I) total incidence of NEC; (II) incidence of feeding intolerance. NEC grading was performed according to Bell's criteria (10).

\section{Search strategy}

We used the literature search function in Endnote X9 
software to search the Ovid, Embase, PubMed, and Web of Science databases using the search key words "probiotics" and "necrotizing enterocolitis", the search process was done from Oct to Nov of 2021.

\section{Literature screening and data extraction}

Two researchers independently reviewed the studies. After eliminating duplicate studies, the researchers screened the articles by title and abstract, following the inclusion criteria for article type, participant type, intervention description, and outcome indicators. Any conflicts of opinion between the two researchers were resolved with the intervention of a third researcher.

Once the initial screening process was complete, the two researchers independently read each selected study and extracted the data, recording it in a pre-prepared form. The extracted data included author name, publication time, number of participants, participants' gestational age, weight, gender, antibiotic use, number of cases in the two study groups, treatment method used in each group, and outcome indicator data for the two groups. All possible efforts were made to obtain data relevant to the selected studies. However, if the data from a study was not accessible, the study was excluded from the meta-analysis.

\section{Bias assessment and quality evaluation}

Risk of bias assessment was performed according to the Cochrane Collaboration Handbook for Systematic Reviews of Intervention from 6 aspects: (I) random allocation method; (II) blind method; (III) implementation of allocation concealment; (IV) data integrity; (V) selective reporting bias; (VI) other biases. We considered a study to be of high quality (grade A) if it met the following criteria: random method, allocation concealment, and blind method; and included the following information: withdrawal or loss to follow-up, intention analysis, and baseline conditions. Grade B was awarded to studies in which these quality evaluation criteria were only partially satisfied (or unclear), and studies in which the criteria were completely unsatisfied were given a grade $\mathrm{C}$.

\section{Statistical analysis}

Stata 16.0 software (Stata Corp LLC, TX, USA) was used for statistical analysis in this meta-analysis. The MantelHaenszel model was used to analyze discrete data (NEC incidence and mortality). Effect sizes were expressed as risk ratios (RRs), and a forest plot was used to display results. We used the Cochran $\mathrm{Q}$ test and $\mathrm{I}^{2}$ to assess the heterogeneity of the studies, with $\mathrm{I}^{2}>50 \%$ or $\mathrm{P}<0.1$ indicating statistically significant heterogeneity. Subgroup heterogeneity was investigated and a L'abbé plot was introduced to show the overall heterogeneity. If the source of heterogeneity was not found, only general descriptive analysis was performed. Funnel plots were used to represent publication bias.

\section{Results}

\section{Literature search results}

Figure 1 shows the results of the literature search and screening process.

\section{Basic characteristics and quality assessment of the included studies}

A total of 10 articles, which collectively included 3,227 patients (11-20), were included in the meta-analysis. The studies were all published between 2005 and 2016. A total of 5 studies $(11-14,17)$ used multi-strain probiotic mixtures in their treatments, while the other $5(15,16,18-20)$ used single-strain probiotic. Newborns in all the studies had a gestational age below 34 weeks and birthweights under 1,500 g (Table 1).

\section{Bias analysis of the selected studies}

Although the randomization methods were not specified, all studies included in this meta-analysis claimed to be randomized. Two studies $(11,17)$ did not mention allocation concealment or blinding. All studies included information about dropouts and withdrawals, with no selective reporting or other biases shown (Table 2).

\section{Meta-analysis results}

\section{Incidences of stage $\geq 2$ NEC}

A total of 7 studies (12-18) reported incidences of stage $\geq 2$ NEC, including 4 studies using multi-strain probiotic treatment and 3 studies using single-strain probiotic treatment. The collective experimental group included 947 patients, and the control group included 946 patients. There was no statistical heterogeneity among the 7 studies $\left(\mathrm{I}^{2}=0 \%\right.$; $\mathrm{P}=0.581$ ). Fixed effects model analysis yielded a pooled $\mathrm{RR}$ 


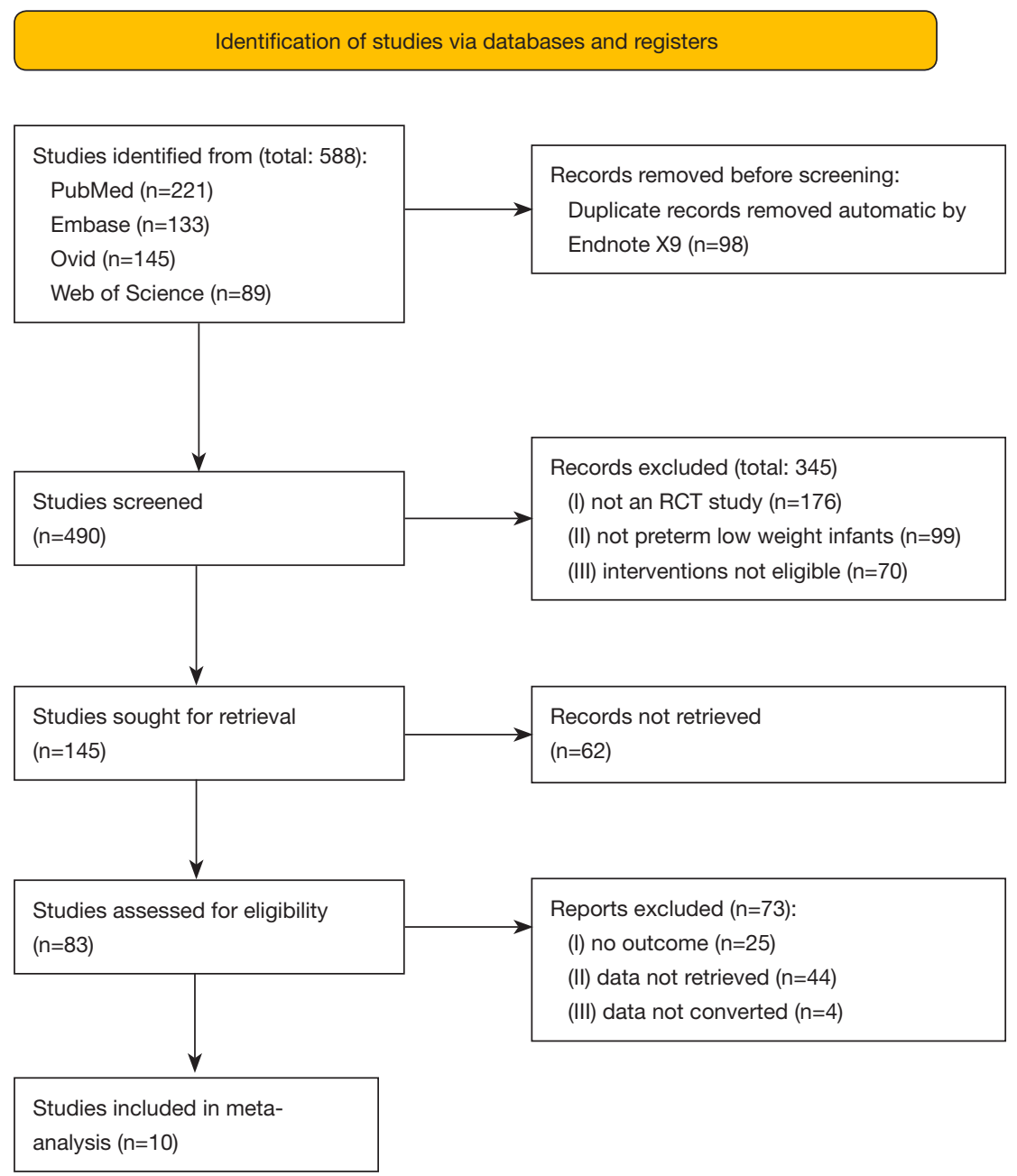

Figure 1 Literature search and screening process flow chart. RCT, randomized controlled trial.

statistic of $0.66,95 \%$ confidence interval (CI): $(0.50,0.87)$, suggesting that intervention with probiotics could reduce the incidence rate of severe NEC $(\mathrm{Z}=-2.978 ; \mathrm{P}=0.003)$. Our meta-analysis divided studies into two subgroups (multiand single-strain), according to whether multiple- or singlestrain probiotic were used in the treatment. There was no heterogeneity in either subgroup. The pooled RR for the multi-strain probiotics group was $0.50,95 \% \mathrm{CI}$ : $(0.32,0.78)$, with a statistically significant difference $(\mathrm{P}=0.002)$. The pooled RR for the single-strain probiotic group was 0.85 , $95 \%$ CI: $(0.61,1.20)$. The difference was not statistically significant $(\mathrm{P}=0.361)$ (Figure 2).

\section{Mortality}

Mortality was reported in all articles (11-20), including 5 studies using multi-strain probiotics and 5 studies using single-strain probiotic. The collective experimental group included 1,723 patients, and there were 1,735 in the control group. There was no statistical heterogeneity among the 10 articles $\left(I^{2}=36.9 \% ; P=0.114\right)$. A fixed effects model analysis yielded a pooled RR of $0.81,95 \%$ CI: $(0.70,0.94)$, suggesting that intervention with probiotics could reduce mortality in underweight preterm infants $(Z=-2.864$; $\mathrm{P}=0.004)$. The pooled RR statistic for the multi-strain probiotics group was $0.63,95 \% \mathrm{CI}:(0.48,0.82)$, with a statistically significant difference $(\mathrm{P}=0.001)$. The pooled $\mathrm{RR}$ for the single-strain probiotic group was $0.94,95 \%$ CI: $(0.80,1.11)$, and the difference was not statistically significant $(\mathrm{P}=0.470)$ (Figure 3).

\section{Incidence of NEC}

Four studies $(11,17,19,20)$ reported the total incidence rate 
Table 1 Basic characteristics of included studies and participants and study quality evaluation scores

\begin{tabular}{|c|c|c|c|c|c|c|c|c|}
\hline Author, year & $\begin{array}{l}\text { Gestational age } \\
\text { (weeks) }\end{array}$ & Birthweight (g) & $\mathrm{E}: \mathrm{C}$ samples & $\begin{array}{c}\text { Experimental group } \\
\text { method }\end{array}$ & $\begin{array}{l}\text { Control group } \\
\text { method }\end{array}$ & $\begin{array}{l}\text { Feeding } \\
\text { method }\end{array}$ & $\begin{array}{l}\text { Outcome } \\
\text { indicators }\end{array}$ & Grade \\
\hline $\begin{array}{l}\text { Bin-Nun et al., } \\
2005 \text { (11) }\end{array}$ & $29.8 \pm 2.6$ & $1,152 \pm 262$ & $72: 73$ & Probiotics mixture 1 & Placebo & $\mathrm{HM}$ & $(a)(b)(d)$ & $A$ \\
\hline Lin et al., 2008 (12) & N/A & $1,028.9 \pm 246.0$ & $217: 217$ & Probiotics mixture 2 & Placebo & $\mathrm{HM}$ & (c)(d) & $B$ \\
\hline $\begin{array}{l}\text { Samanta et al., } \\
2009 \text { (13) }\end{array}$ & $30.12 \pm 1.63$ & $1,172 \pm 143$ & $91: 95$ & Probiotics mixture 1 & Placebo & HM & $(c)(d)(e)$ & $\mathrm{B}$ \\
\hline $\begin{array}{l}\text { Braga et al., } \\
2011 \text { (14) }\end{array}$ & $29.5 \pm 2.5$ & $1,194.7 \pm 206.3$ & 119:112 & Probiotics mixture 2 & Placebo & HM & (c)(d) & $\mathrm{B}$ \\
\hline $\begin{array}{l}\text { Sari et al., } \\
2011 \text { (15) }\end{array}$ & $29.5 \pm 2.4$ & $1,231 \pm 262$ & 110:111 & $\begin{array}{l}\text { Lactobacillus } \\
\text { sporogenes }\end{array}$ & Placebo & $\mathrm{HM}$ & $(c)(d)(f)$ & $A$ \\
\hline $\begin{array}{l}\text { Demirel et al., } \\
2013 \text { (16) }\end{array}$ & 28.0 (range, 17-45) & $1,164 \pm 261$ & $135: 136$ & $\begin{array}{c}\text { Saccharomyces } \\
\text { boulardii }\end{array}$ & Placebo & $\mathrm{HM}$ & $(c)(d)(e)(f)$ & $B$ \\
\hline $\begin{array}{l}\text { Oncel et al., } \\
2014 \text { (18) }\end{array}$ & $28.2 \pm 2.4$ & $1,071 \pm 274$ & 200:200 & Lactobacillus reuteri & Placebo & $\mathrm{HM}$ & $(a)(c)(d)(e)(f)$ & $A$ \\
\hline $\begin{array}{l}\text { Van Niekerk et al., } \\
2015 \text { (19) }\end{array}$ & $24-34$ & $500-1,250$ & $54: 56$ & $\begin{array}{l}\text { Lactobacillus } \\
\text { rhamnosus GG }\end{array}$ & Placebo & $\mathrm{HM}$ & (a)(d) & $A$ \\
\hline $\begin{array}{l}\text { Costeloe et al., } \\
2016 \text { (20) }\end{array}$ & $28(26.1-29.1)$ & $1,039 \pm 312$ & $650: 660$ & $\begin{array}{c}\text { Bifidobacterium } \\
\text { breve }\end{array}$ & Placebo & $\mathrm{HM}$ & (a)(d) & $A$ \\
\hline
\end{tabular}

multiple-strain probiotics: 1= Bifidobacteria infantis, Streptococcus thermophilus, and Bifidobacteria bifidus; $2=$ Bifidobacterium and Lactobacillus; 3= Lactobacillus acidophilus, Lactobacillus rhamnosus, Lactobacillus casei, Lactobacillus plantarum, Bifidobacteruim infantis, and Streptococcus thermophilus. Outcome indicators: (a) overall NEC incidence, (b) NEC severity score, (c) NEC stage $\geq 2$, (d) mortality, (e) length of stay, (f) feeding intolerance. E:C, experimental: control; N/A, not available; HM, human milk; NEC, neonatal necrotizing enterocolitis.

Table 2 Risk of bias assessment based on Cochrane Collaboration criteria

\begin{tabular}{|c|c|c|c|c|c|c|}
\hline Study & $\begin{array}{c}\text { Random sequence } \\
\text { generation }\end{array}$ & $\begin{array}{c}\text { Allocation } \\
\text { concealment }\end{array}$ & Blind method & Data integrity & $\begin{array}{l}\text { Optional } \\
\text { reporting }\end{array}$ & Other bias \\
\hline Bin-Nun et al., 2005 (11) & Low & Unclear & Unclear & Low & Low & Low \\
\hline Samanta et al., 2009 (13) & Low & Low & Low & Low & Low & Low \\
\hline Braga et al., 2011 (14) & Low & Low & Low & Low & Low & Low \\
\hline Demirel et al., 2013 (16) & Low & Low & Low & Low & Low & Low \\
\hline Fernández-Carrocera et al., 2013 (17) & Low & Unclear & Unclear & Low & Low & Low \\
\hline Oncel et al., 2014 (18) & Low & Low & Low & Low & Low & Low \\
\hline
\end{tabular}


$\%$

Weight

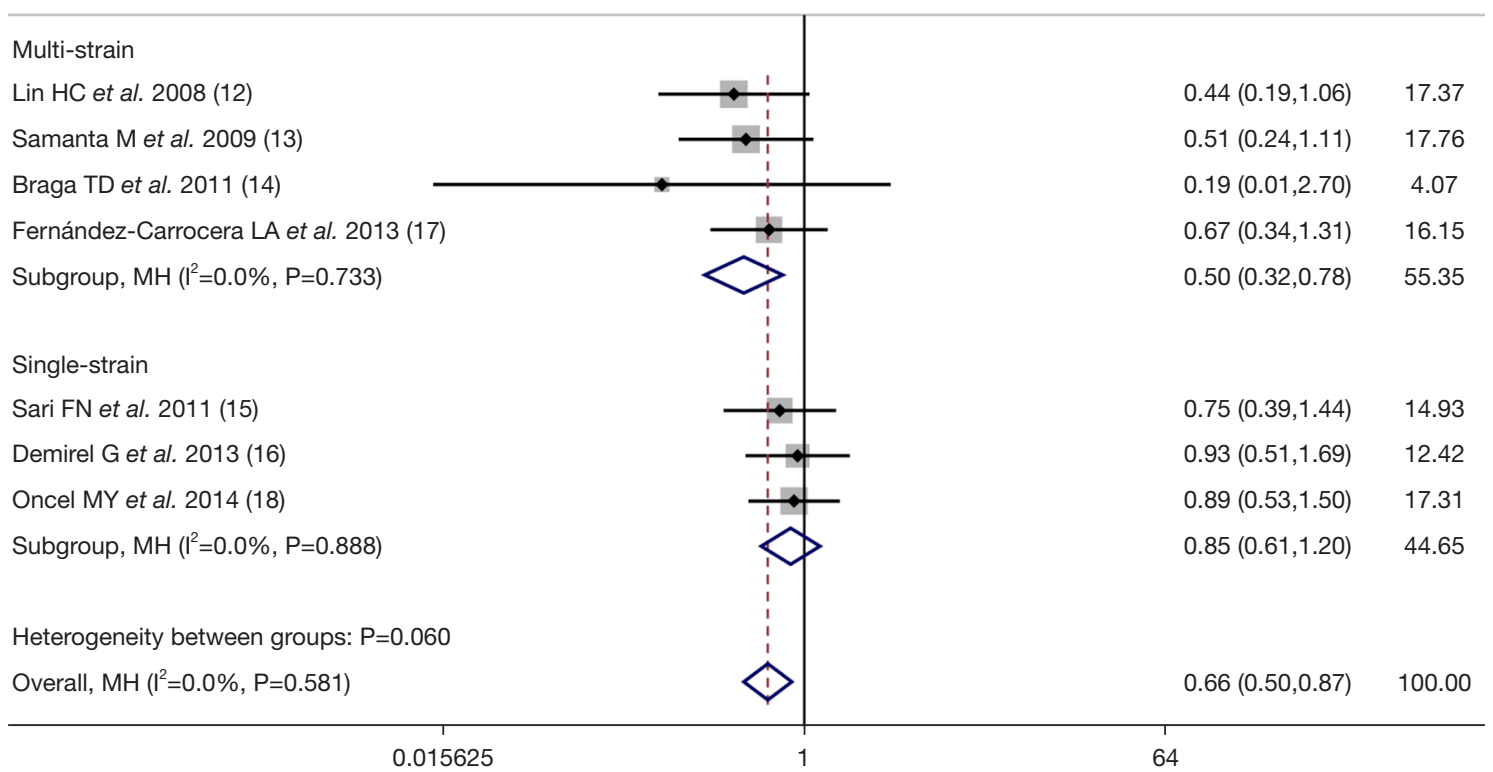

NOTE: Weights and between-subgroup heterogeneity test are from Mantel-Haenszel model

Figure 2 Preventive effect of probiotics on severe NEC (12-18). NEC, neonatal necrotizing enterocolitis; CI, confidence interval.

\begin{tabular}{|c|c|c|}
\hline Probiotic group, study, and heterogeneity & $\begin{array}{l}\text { Risk ratio } \\
(95 \% \mathrm{Cl})\end{array}$ & $\begin{array}{c}\% \\
\text { Weight }\end{array}$ \\
\hline \multicolumn{3}{|l|}{ Multi-strain } \\
\hline Bin-Nun et al. 2005 (11) & $0.53(0.26,1.07)$ & 7.40 \\
\hline Lin HC et al. 2008 (12) & $0.33(0.14,0.82)$ & 8.54 \\
\hline Samanta M et al. 2009 (13) & $0.45(0.19,1.09)$ & 6.03 \\
\hline Braga TD et al. 2011 (14) & $0.95(0.70,1.29)$ & 16.68 \\
\hline Fernández-Carrocera LA et al. 2013 (17) - & $0.25(0.04,1.57)$ & 2.85 \\
\hline Subgroup, $\mathrm{MH}\left(\mathrm{I}^{2}=63.5 \%, \mathrm{P}=0.027\right)$ & $0.63(0.48,0.82)$ & 41.51 \\
\hline \multicolumn{3}{|l|}{ Single-strain } \\
\hline Sari FN et al. 2011 (15) & $0.86(0.36,2.05)$ & 2.54 \\
\hline Demirel G et al. 2013 (16) & $1.00(0.53,1.89)$ & 3.61 \\
\hline Oncel MY et al. 2014 (18) & $0.86(0.58,1.27)$ & 12.09 \\
\hline Van Nickerk E et al. 2015 (19) & $0.58(0.18,1.91)$ & 2.43 \\
\hline Costeloe K et al., 2016 (20) & $0.99(0.81,1.21)$ & 37.82 \\
\hline Subgroup, $\mathrm{MH}\left(\mathrm{I}^{2}=0.0 \%, \mathrm{P}=0.883\right)$ & $0.94(0.80,1.11)$ & 58.49 \\
\hline \multicolumn{3}{|l|}{ Heterogeneity between groups: $P=0.012$} \\
\hline Overall, $\mathrm{MH}\left(\mathrm{I}^{2}=36.9 \%, \mathrm{P}=0.114\right)$ & $0.81(0.70,0.94)$ & 100.00 \\
\hline
\end{tabular}

NOTE: Weights and between-subgroup heterogeneity test are from Mantel-Haenszel model

Figure 3 Effect of probiotics on reducing mortality in underweight neonates (11-20). CI, confidence interval. 


\begin{tabular}{|c|c|c|}
\hline Probiotic group, study, and heterogeneity & $\begin{array}{l}\text { Risk ratio } \\
(95 \% \mathrm{Cl})\end{array}$ & $\begin{array}{c}\% \\
\text { Weight }\end{array}$ \\
\hline Bin-Nun et al. 2005 (11) & $0.40(0.14,1.12)$ & 8.84 \\
\hline Fernández-Carrocera LA et al. 2013 (17) & $0.67(0.34,1.31)$ & 10.53 \\
\hline Van Niekerk E et al. 2015 (19) & $0.68(0.26,1.74)$ & 5.35 \\
\hline Costeloe K et al. 2016 (20) & $0.97(0.80,1.17)$ & 75.27 \\
\hline Overall, $\mathrm{MH}\left(\mathrm{I}^{2}=29.4 \%, \mathrm{P}=0.236\right)$ & $0.87(0.73,1.04)$ & 100.00 \\
\hline
\end{tabular}

NOTE: Weights are from Mantel-Haenszel model

Figure 4 Effect of probiotics on reducing the overall incidence of NEC $(11,17,19,20)$. NEC, neonatal necrotizing enterocolitis; CI, confidence interval.

Probiotic group, study, and heterogeneity
Sari FN et al. 2011 (15)
Demirel G et al. $2013(16)$
Oncel $\mathrm{MY}$ et al. $2014(18)$

NOTE: Weights are from Mantel-Haenszel model

Figure 5 Effect of probiotics on feeding intolerance $(15,16,18)$. CI, confidence interval.

of NEC. There was no statistical heterogeneity among the 4 studies $\left(\mathrm{I}^{2}=29.4 \% ; \mathrm{P}=0.236\right)$. A fixed effects model analysis yielded a pooled RR of $0.87,95 \%$ CI: $(0.73,1.04)$, $\mathrm{Z}=-1.513$, and the difference was not statistically significant $(\mathrm{P}=0.130)$, suggesting that probiotics did not reduce the total incidence rate of NEC (Figure 4).

\section{Feeding intolerance}

Three studies $(15,16,18)$ reported the incidence of neonatal feeding intolerance. There was no statistical heterogeneity among the studies $\left(\mathrm{I}^{2}=0 \% ; \mathrm{P}=0.433\right)$. A fixed effects model analysis yielded a pooled RR statistic of $0.78,95 \%$ CI: (0.67, 0.90), $Z=-3.280$, and the difference was statistically significant $(\mathrm{P}=0.001)$, suggesting that fewer cases of feeding intolerance occurred with probiotic intervention (Figure 5).

\section{Heterogeneity and subgroup analysis}

A L'abbé plot was used to assess heterogeneity in the subgroup analysis of mortality rates. It was found that the studies clustered into two groups, corresponding to the two probiotic-based subgroups (multiple- and single-strain). The main source of heterogeneity between the studies was whether the probiotics used were single- or multiple-strain (Figure 6).

\section{Sensitivity analysis}

In the sensitivity analysis for mortality, impact factor analysis showed that all 10 studies had a sensitivity of between 0.70 and 0.94 , indicating that the stability of the results was good (Figure 7).

\section{Analysis of publication bias}

A funnel plot was drawn up to assess bias analysis. The distribution of all 10 studies included in this meta-analysis remained uneven within the funnel, suggesting a small 
possibility of publication bias (Figure 8).

\section{Discussion}

This meta-analysis evaluated 10 high-quality controlled clinical studies that collectively included a total of 3,227 premature infants with low bodyweight. Our results showed that the proportion of newborns with severe NEC (stage $\geq 2$ ) was significantly lower in the experimental groups who took preventive probiotics than that in the control groups. The mortality rate was also significantly lower

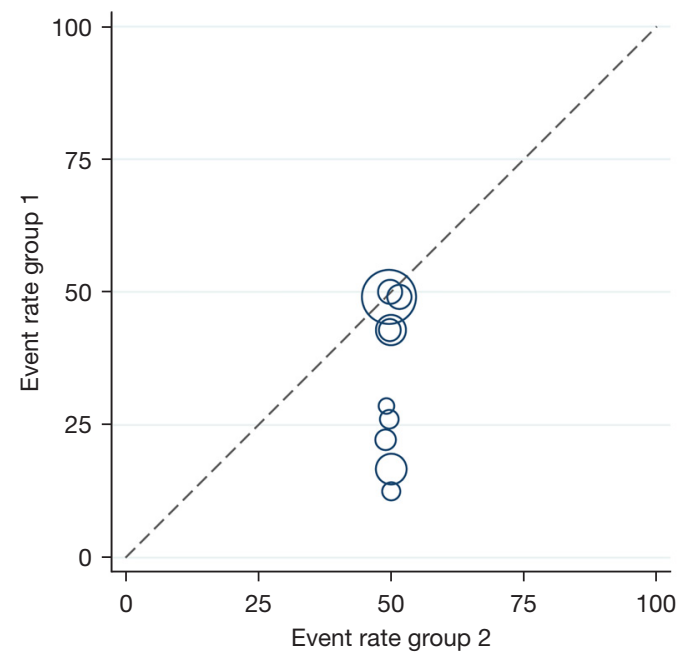

Figure 6 Heterogeneity analysis for mortality. in the experimental groups than in the control groups, consistent with the results of previous studies $(21,22)$. It should be noted that concerning the overall incidence rate of NEC, we found differences between the experimental and control groups to be not statistically significant, which is inconsistent with the results of a previous study (9). This discrepancy may have arisen because only 4 studies in the present meta-analysis reported the overall incidence rate of NEC, resulting in insufficient data. Despite this, the results of this meta-analysis confirmed the role of probiotics in preventing severe NEC and reducing mortality in preterm, underweight neonates.

Dysregulation of intestinal bacteria is an important cause of neonatal NEC, which is characterized by reduced

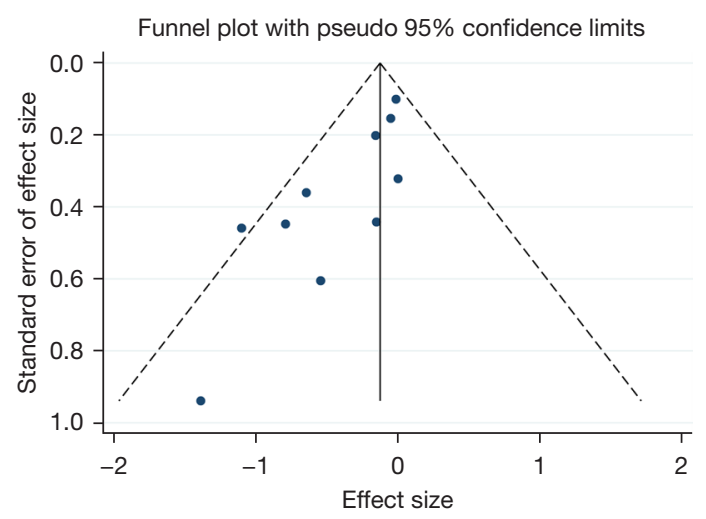

Figure 8 Funnel plot analysis of bias for mortality.

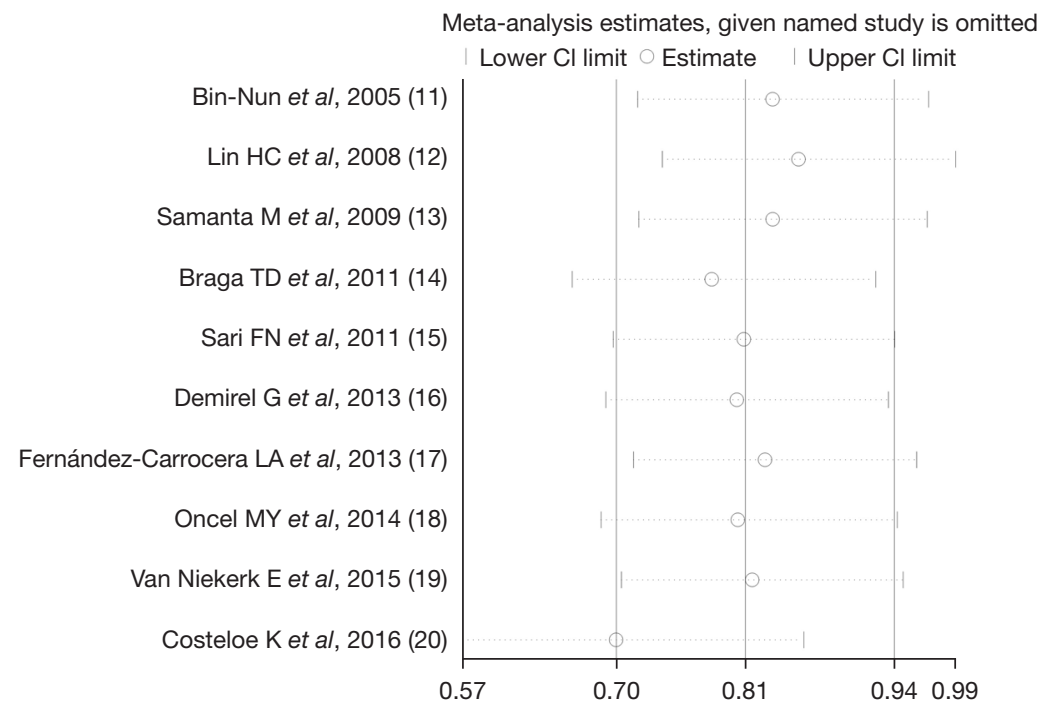

Figure 7 Sensitivity analysis for mortality (11-20). CI, confidence interval. 
intestinal microbial diversity, reduced colonization of beneficial microorganisms such as Bifidobacteria, Pirobacterium and Lactobacilli, and an increase in the number of harmful bacteria (23). Probiotics can play a 3 -fold role, regulating the structure of intestinal bacteria and inhibiting the growth of harmful germs, promoting the improvement of intestinal barrier function structure and accelerating the maturation of intestinal function, and regulating intestinal immunity and inhibiting the inflammatory response (24). Bifidobacteria can reduce plasma endotoxin levels by inhibiting bacterial translocation in the large intestine (25). Lactobacillus rhamnosus can then increase the intestinal lactic acid bacteria content and inhibit the transfer of pathogens through the intestinal barrier to extraintestinal organs (26).

However, some studies (20) have also revealed that although the application of Bifidobacterium breve in premature infants is safe, it has no significant effect on the incidence of NEC. In this meta-analysis, studies were divided into multi-strain and single-strain groups according to the characteristics of the probiotic treatment. Results showed that multi-strain mixtures of probiotics had a significant effect on reducing severe NEC and mortality, while single-strain probiotic had no significant effect. Jiang et al. (27) conducted a meta-analysis of studies that included 1,869 Asian neonates treated with multi- and single-strain probiotic. Their results showed that multiplestrain probiotics had a better preventive effect for severe NEC than single-strain probiotic, consistent with the present meta-analysis. It has been speculated that the combination of multiple probiotics can significantly increase the number of beneficial intestinal flora in underweight, premature infants while reducing Clostridium perfringens and Enterobacteriaceae. Hence, the multiple-strain-strain probiotics are better for the prevention of NEC (28).

In the studies included in our meta-analysis, the most frequently used probiotics were Lactobacillus rbamnosus $G G$, Bifidobacterium, and Lactobacillus. Although the effectiveness of the different probiotics was not compared in this metaanalysis, a reticular meta-analysis by Beghetti et al. (29), included 29 different probiotic treatments and showed that Lactobacillus rhamnosus $G G$ was the most effective in reducing the incidence of NEC, while Lactobacillus acidophilus $L B$ was the most effective in preventing severe NEC.

Although some studies (30) claim that the use of probiotics may increase the probability of neonatal infection, no serious adverse reactions were reported in the 10 studies included in our meta-analysis. In addition, the incidence of feeding intolerance in the experimental groups was lower than in the control groups, which demonstrated that the use of probiotics was safe. The children included in these 10 studies were breastfed. Study (31) has shown that combining Bifidobacteria with breastfeeding promoted the bacteria's colonization of the intestinal tract and reduced the number of Enterobacteriaceae, thereby reducing the incidence of NEC.

To investigate the source of heterogeneity in the studies, we analyzed them according to the type of probiotics used (multi- or single-strain), and our results showed that the type of probiotics used was the greatest source of heterogeneity. Sensitivity analysis showed that the results of our meta-analysis were stable.

We also assessed the quality and bias of the 10 selected controlled clinical studies. Our evaluation showed that the quality of the studies was high, however, neither literature (11) nor literature (17) described the allocation concealment method and blind method, which might resulting in some implementation bias for the analysis. Publication bias analysis showed that the literature on both sides of the funnel was unevenly distributed, which might indicate a small publication bias. And there were some limitations to our meta-analysis, including the lack of subgroup analysis for the different feeding methods (breastfeeding or formula feeding) or different probiotic species, which are worthy of further research.

\section{Conclusions}

In summary, the addition of probiotics to the diet of lowbirthweight premature infants can reduce the incidence of severe NEC and associated mortality. However, based on the small implementation bias and publication bias in the literatures, the preventive effect of probiotics on NEC is still worthy of further discussion.

\section{Acknowledgments}

Funding: None.

\section{Footnote}

Reporting Checklist: The authors have completed the PRISMA reporting checklist. Available at https:// tp.amegroups.com/article/view/10.21037/tp-22-27/rc

Conflicts of Interest: All authors have completed the ICMJE 
uniform disclosure form (available at https://tp.amegroups. com/article/view/10.21037/tp-22-27/coif). The authors have no conflicts of interest to declare.

Ethical Statement: The authors are accountable for all aspects of the work in ensuring that questions related to the accuracy or integrity of any part of the work are appropriately investigated and resolved.

Open Access Statement: This is an Open Access article distributed in accordance with the Creative Commons Attribution-NonCommercial-NoDerivs 4.0 International License (CC BY-NC-ND 4.0), which permits the noncommercial replication and distribution of the article with the strict proviso that no changes or edits are made and the original work is properly cited (including links to both the formal publication through the relevant DOI and the license). See: https://creativecommons.org/licenses/by-nc-nd/4.0/.

\section{References}

1. Roy A, Tayeb M, Al-Khogeer S. Outcome in definite and advanced neonatal necrotizing enterocolitis. Saudi Med J 2004;25:746-52.

2. O'Connell JS, Li B, Zito A, et al. Treatment of necrotizing enterocolitis by conditioned medium derived from human amniotic fluid stem cells. PLoS One 2021;16:e0260522.

3. Meister AL, Gardner FC, Browning KN, et al. Vagal Tone and Proinflammatory Cytokines Predict Feeding Intolerance and Necrotizing Enterocolitis Risk. Adv Neonatal Care 2021;21:452-61.

4. Kelleher ST, McMahon CJ, James A. Necrotizing Enterocolitis in Children with Congenital Heart Disease: A Literature Review. Pediatr Cardiol 2021;42:1688-99.

5. Gephart SM, Newnam K, Weiss A, et al. Feasibility and Acceptability of a Neonatal Project ECHO (NeoECHO) as a Dissemination and Implementation Strategy to Prevent Necrotizing Enterocolitis. Worldviews Evid Based Nurs 2021;18:361-70.

6. Yan X, Sangild PT, Peng Y, et al. Supplementary Bovine Colostrum Feedings to Formula-Fed Preterm Pigs Improve Gut Function and Reduce Necrotizing Enterocolitis. J Pediatr Gastroenterol Nutr 2021;73:e39-46.

7. Li B, Wu RY, Horne RG, et al. Human Milk Oligosaccharides Protect against Necrotizing Enterocolitis by Activating Intestinal Cell Differentiation. Mol Nutr Food Res 2020;64:e2000519.
8. Que J, Van Oerle R, Albersheim S, et al. The effect of daily probiotics on the incidence and severity of necrotizing enterocolitis in infants with very low birth weight. Can J Surg 2021;64:E644-9.

9. Athalye-Jape G, Rao S, Patole S. Effects of probiotics on experimental necrotizing enterocolitis: a systematic review and meta-analysis. Pediatr Res 2018;83:16-22.

10. Juhl SM, Hansen ML, Gormsen M, et al. Staging of necrotising enterocolitis by Bell's criteria is supported by a statistical pattern analysis of clinical and radiological variables. Acta Paediatr 2019;108:842-8.

11. Bin-Nun A, Bromiker R, Wilschanski M, et al. Oral probiotics prevent necrotizing enterocolitis in very low birth weight neonates. J Pediatr 2005;147:192-6.

12. Lin HC, Hsu CH, Chen HL, et al. Oral probiotics prevent necrotizing enterocolitis in very low birth weight preterm infants: a multicenter, randomized, controlled trial. Pediatrics 2008;122:693-700.

13. Samanta M, Sarkar M, Ghosh P, et al. Prophylactic probiotics for prevention of necrotizing enterocolitis in very low birth weight newborns. J Trop Pediatr 2009;55:128-31.

14. Braga TD, da Silva GA, de Lira PI, et al. Efficacy of Bifidobacterium breve and Lactobacillus casei oral supplementation on necrotizing enterocolitis in very-lowbirth-weight preterm infants: a double-blind, randomized, controlled trial. Am J Clin Nutr 2011;93:81-6.

15. Sari FN, Dizdar EA, Oguz S, et al. Oral probiotics: Lactobacillus sporogenes for prevention of necrotizing enterocolitis in very low-birth weight infants: a randomized, controlled trial. Eur J Clin Nutr 2011;65:434-9.

16. Demirel G, Erdeve O, Celik IH, et al. Saccharomyces boulardii for prevention of necrotizing enterocolitis in preterm infants: a randomized, controlled study. Acta Paediatr 2013;102:e560-5.

17. Fernández-Carrocera LA, Solis-Herrera A, CabanillasAyón M, et al. Double-blind, randomised clinical assay to evaluate the efficacy of probiotics in preterm newborns weighing less than $1500 \mathrm{~g}$ in the prevention of necrotising enterocolitis. Arch Dis Child Fetal Neonatal Ed 2013;98:F5-9.

18. Oncel MY, Sari FN, Arayici S, et al. Lactobacillus Reuteri for the prevention of necrotising enterocolitis in very low birthweight infants: a randomised controlled trial. Arch Dis Child Fetal Neonatal Ed 2014;99:F110-5.

19. Van Niekerk E, Nel DG, Blaauw R, et al. Probiotics Reduce Necrotizing Enterocolitis Severity in HIV-exposed 
Premature Infants. J Trop Pediatr 2015;61:155-64.

20. Costeloe K, Hardy P, Juszczak E, et al. Bifidobacterium breve BBG-001 in very preterm infants: a randomised controlled phase 3 trial. Lancet 2016;387:649-60.

21. Seghesio E, De Geyter C, Vandenplas Y. Probiotics in the Prevention and Treatment of Necrotizing Enterocolitis. Pediatr Gastroenterol Hepatol Nutr 2021;24:245-55.

22. Sawh SC, Deshpande S, Jansen S, et al. Prevention of necrotizing enterocolitis with probiotics: a systematic review and meta-analysis. PeerJ 2016;4:e2429.

23. Martin CR, Walker WA. Probiotics: role in pathophysiology and prevention in necrotizing enterocolitis. Semin Perinatol 2008;32:127-37.

24. Lin PW, Nasr TR, Stoll BJ. Necrotizing enterocolitis: recent scientific advances in pathophysiology and prevention. Semin Perinatol 2008;32:70-82.

25. Juber BA, Boly TJ, Pitcher GJ, et al. Routine Administration of a Multispecies Probiotic Containing Bifidobacterium and Lactobacillus to Very Low Birth Weight Infants Had No Significant Impact on the Incidence of Necrotizing Enterocolitis. Front Pediatr 2021;9:757299.

26. Chandran S, Anand AJ, Rajadurai VS, et al. EvidenceBased Practices Reduce Necrotizing Enterocolitis and Improve Nutrition Outcomes in Very Low-Birth-Weight

Cite this article as: Liu H, Wang B, Lu T, Pei Y. Safety and efficacy of probiotics in the prevention of necrotizing enterocolitis in premature and/or low-birthweight infants: a systematic review and meta-analysis. Transl Pediatr 2022;11(2):249-259. doi: 10.21037/tp-22-27
Infants. JPEN J Parenter Enteral Nutr 2021;45:1408-16.

27. Jiang T, Zhang $\mathrm{H}, \mathrm{Xu} \mathrm{X}$, et al. Mixed probiotics decrease the incidence of stage II-III necrotizing enterocolitis and death: A systematic review and meta-analysis. Microb Pathog 2020;138:103794.

28. Ishizeki S, Sugita M, Takata M, et al. Effect of administration of bifidobacteria on intestinal microbiota in low-birth-weight infants and transition of administered bifidobacteria: a comparison between one-species and three-species administration. Anaerobe 2013;23:38-44.

29. Beghetti I, Panizza D, Lenzi J, et al. Probiotics for Preventing Necrotizing Enterocolitis in Preterm Infants: A Network Meta-Analysis. Nutrients 2021;13:192.

30. Angurana SK, Bansal A, Singhi S, et al. Evaluation of Effect of Probiotics on Cytokine Levels in Critically Ill Children With Severe Sepsis: A Double-Blind, PlaceboControlled Trial. Crit Care Med 2018;46:1656-64.

31. DI Pierro F, Lo Russo P, Danza ML, et al. Use of a probiotic mixture containing Bifidobacterium animalis subsp. lactis BB-12 and Enterococcus faecium L3 as prophylaxis to reduce the incidence of acute gastroenteritis and upper respiratory tract infections in children. Minerva Pediatr (Torino) 2021;73:222-9.

(English Language Editor: L. Roberts) 